\title{
Erradicação do herpesvírus bovino - 1 (BHV-1) de um rebanho bovino leiteiro em manejo semi-intensivo ${ }^{1}$
}

\author{
Claudia Del Fava ${ }^{2}$, Eliana De Stefano ${ }^{3}$, Edviges Maristela Pituco ${ }^{3}$, Maria Cristina V. \\ Bilynskyj $^{3}$, Líria Hiromi Okuda ${ }^{3}$, Claudia Rodrigues Pozzi ${ }^{2}$, Cecília José Veríssimo ${ }^{2}$ \\ e João J. A. Abreu Demarchi
}

\begin{abstract}
Del Fava C., De Stefano E., Pituco E.M., Bilynskyj M.C.V., Okuda L.H., Pozzi, C.R., Veríssimo C.J. \& Demarchi J.J.A.A. 1998. [Eradication of Herpesvirus Bovine-1 (BHV-1) from a dairy cattle herd with a semi-intensive management.] Erradicação do Herpesvírus Bovino-1 (BHV-1) de um rebanho bovino leiteiro em manejo semi-intensivo. Pesquisa Veterinária Brasileira 18(2):61-68. Instituto de Zootecnia, Cx. Postal 60, Nova Odessa, SP 13460-000, Brazil.

To eradicate the BHV-1 from a dairy cattle herd without vaccination, a preliminary serological survey was performed in 154 animals, that revealed $15.6 \%$ seropositives for BHV-1. The test used was serum neutralization with the microtitration technique. The seropositive nonpregnant cows were immediately eliminated from the herd and the pregnant cows were isolated and eliminated after parturiation. The calves with colostral antibodies were kept in the herd. There were no seropositive animals between the 6 to 12 months old calves and the heifers. The animals were monitored serologically every 3 months for 21 months and afterwords in 2 semestral intervals. The seropositive nonpregnant, pregnant and the nursing cows were the source of BHV-1 infecction. In order to maintain a BHV-1 free herd, measurements of control had been taken, as the utilization of virus-free semen, quarantine when animals were introduced into the herd, and semestral serological surveys. Through these measurements the farm has been BHV-1 free for 18 months.
\end{abstract}

INDEX TERMS: Eradication, BHV-1, dairy cattle.

RESUMO.- Com o objetivo de erradicar o BHV-1 de um rebanho bovino leiteiro de alto valor genético sem a utilização de vacina, foi realizado um exame sorológico prévio em 154 animais, onde constatou-se $15,6 \%$ de reagentes ao BHV-1. A técnica utilizada foi a soroneutralização em microplacas. Dentre os animais soropositivos, as vacas vazias foram descartadas imediatamente e as prenhes isoladas e descartadas após o parto. Os bezerros apresentaram anticorpos colostrais até os seis meses de idade, motivo pelo qual não foram descartados; nos bezerros de 6 a 12 meses de idade e nas novilhas não foram diagnosticados animais soropositivos. Os animais foram examinados trimestralmente, por 21 meses, seguido de mais duas coletas semestrais. As vacas secas, prenhes e em lactação, soropositivas, revelaram ser a fonte de infecção do BHV-1. A manutenção de rebanho livre é possí-

\footnotetext{
${ }^{1}$ Aceito para publicação em 18 de fevereiro de 1998.

${ }^{2}$ Instituto de Zootecnia, Cx. Postal 60, Nova Odessa, SP 13460-000.

${ }^{3}$ Instituto Biológico, Av. Cons. Rodrigues Alves 1252, São Paulo, SP 04014-002.
}

vel, desde que sejam adotadas medidas como a utilização de sêmen livre de BHV-1, realização de quarentena no ingresso de animais e exames sorológicos anuais visando impedir a reintrodução do vírus. Com o conjunto destas medidas adotadas, a fazenda encontra-se há 18 meses livre do BHV-1.

TERMOS DE INDEXAÇÃO: Erradicação, BHV-1, bovinos leiteiros.

\section{INTRODUÇÃO}

O Herpesvírus Bovino tipo-1 (BHV-1), agente etológico da Rinotraqueíte Infecciosa Bovina/Vulvovaginite Pustular Infecciosa (IBR/IPV) (Roizman et al. 1995), é responsável por uma variedade de sinais clínicos como rinotraqueíte, abortamento, conjuntivite, vulvovaginite e balanopostite. Como todos os Alfaherpesvírus, o BHV-1 permanece em estado de latência, alojando-se nos gânglios nervosos, principalmente no trigêmeo e sacral, podendo ser reativado em situações estressantes como parto, transporte, vacinações ou com a administração prolongada de corticóides (Ackermann et al. 1982). O BHV-1 é excretado pelas secreções respiratórias, oculares, genitais e sêmen de bo- 
vinos infectados. A transmissão ocorre principalmente por contato direto através de aerossóis, monta natural, inseminação artificial ou por contato indireto através de fômites (Lemaire et al. 1994).

As enfermidades causadas pelo BHV-1 provocam sérios prejuízos à pecuária nacional, especialmente em bovinos de exploração leiteira, onde há queda da produção de leite e diminuição no índice de fertilidade. Há também restrições ao comércio internacional de animais vivos e seus produtos como sêmen e embriões (Lemaire et al. 1994). Estas restrições estão previstas no Código Internacional de Saúde Animal (OIE,1995), como exigência para os países importadores, por ser considerada enfermidade de importância sócio-econômica dentro das fronteiras dos países.

Dados de ocorrência e prevalência do BHV-1 demonstram que $o$ agente está disseminado nos rebanhos bovinos brasileiros (Pituco, 1988, Anunciação et al. 1989, Lovato et al. 1995, Vidor et al. 1995). Em 30.151 amostras examinadas na Seção de Febre Aftosa do Instituto Biológico, no período de 1985 a 1997, observou-se $37 \%$ (11.162) amostras positivas, provenientes de rebanhos com problemas reprodutivos, de vários estados brasileiros (Pituco, 1997, dados não publicados).

A vacinação de bovinos minimiza as manifestações clínicas da doença, porém, as vacinas disponíveis atualmente não impedem a latência do BHV-1 e não eliminam o vírus já instalado. Um animal infectado pelo BHV-1, mesmo vacinado, poderá reativar e eliminar o vírus (Lemaire et al., 1994). Além disso, as vacinas comercializadas no Brasil não permitem a distinção entre animais vacinados dos infectados com vírus de campo, dificultando a erradicação do BHV-1 da propriedade. A vacinação de rebanhos de alto padrão zootécnico com baixa prevalência de infecção não é recomendada, sendo adotado nestes casos o descarte dos animais soropositivos (Straub 1991), para atingir o mais brevemente possível a erradicação. Bradley (1985) e Ackermann et al. (1990) obtiveram sucesso ao realizarem programa de erradicação do BHV-1 em plantéis bovinos de carne submetidos à manejo extensivo e confinamento, respectivamente, através de exames sorológicos realizados periodicamente, associados à medidas de isolamento e descarte dos animais infectados. Observaram que eliminando a fonte de infecção e utilizando fêmeas de reposição (novilhas) livres do BHV-1, era possível manter as propriedades indenes da enfermidade.

Considerando as exigências do comércio internacional de animais e de produtos de biotecnologia com relação ao BHV-1 e que seu combate para a obtenção de rebanhos bovinos leiteiros de alto padrão genético livres pode ser efetuado com medidas práticas de manejo sanitário, objetivou-se com o presente trabalho demonstrar que práticas de erradicação sem vacinação, podem ser implantadas no Brasil.

\section{MATERIAL E MÉTODOS}

Foram utilizados bovinos da raça Holandesa e Pardo Suíça, em propriedade fornecedora de leite tipo B, no Setor Palmeiras, Instituto de Zootecnia, em Nova Odessa, Estado de São Paulo, Brasil. O município localiza-se na latitude 22o42'00"S, longitude 47o18'00"W, com temperatura média anual de $22,30 \mathrm{o}$, precipitação média anual $1.300 \mathrm{~mm}$ e altitude de $550 \mathrm{~m}$ (Embrapa 1978).
Após um estudo de prevalência da infecção, quando verificou-se a mãe até 2 dias de vida para mamarem o colostro, sendo a seguir transferidos para gaiolas individuais, onde a alimentação consistia de leite ( $10 \%$ de seu peso vivo), concentrado comercial peletizado e feno até 2 meses de idade, quando eram desmamados. Dos 2 aos 6 meses eram mantidos em baias coletivas com suplementação de feno e concentrado e dos 6 meses até um ano permaneciam em piquetes com suplementação de volumoso e concentrado.

b) Novilhas: as fêmeas com idade superior a 12 meses foram mantidas em piquetes e suplementadas com volumoso e concentrado quando necessário. Ao atingirem $350 \mathrm{~kg}$, eram transferidas para o lote de vacas secas para serem inseminadas.

c) Vacas secas: vacas não lactantes e novilhas vazias permaneciam em piquetes, onde eram suplementadas com volumoso e concentrado quando necessário. Uma vez inseminadas e confirmada a prenhez, eram transferidas para o lote de vacas prenhes.

d) Vacas prenhes: fêmeas com diagnóstico de gestação positivo eram mantidas em piquetes e suplementadas com volumoso e concentrado quando necessário.

e) Vacas em lactação: as vacas paridas eram divididas em três lotes, de acordo com o período de lactação (início, meio e fim) e submetidas à duas ordenhas diárias (ordenha mecânica).

0 manejo reprodutivo era efetuado em duas estações de monta, com duração de 2 meses, uma no primeiro e outra no segundo semestre. A inseminação artificial era efetuada com sêmen controlado para BHV-1.

O manejo sanitário da fazenda compreendia monitoramento sorológico semestral para brucelose e leptospirose e intradermoreação na prega da cauda para tuberculose. A aplicação de vacina contra febre aftosa e brucelose foi efetuada de acordo com normas oficiais da Defesa Sanitária Animal. Procedeu-se também a imunização contra clostridiose aos 6, 12 e 24 meses, controle estratégico de carrapatos com 3 aplicações de carrapaticida em intervalo menor de 21 dias no início da primavera e final do verão e aplicação de vermífugo de acordo com a contagem de ovos pôr grama de fezes.

Todos os animais foram sistematicamente monitorados para BHV1. A primeira coleta de sangue foi efetuada em novembro de 1994 , sendo reexaminados um mês após, para identificar animais em incubação. A seguir, realizaram-se 6 coletas em intervalos trimestrais e duas coletas semestrais $\left(27^{\circ}\right.$ e $33^{\circ}$ meses).

Não houve ingresso de animais na propriedade. Também não houve movimentação dos animais da fazenda para exposições ou leilões e as condições de manejo de pastagens não permitiram contato do rebanho com animais de propriedades vizinhas.

As fêmeas adultas soropositivas não gestantes foram descartadas do rebanho após o início do estudo e as fêmeas gestantes foram mantidas em pastos isolados, até a parição, permitindo que os bezerros mamassem colostro e então, foram descartadas.

Teste de soroneutralização: as amostras de soro foram examinadas através da soroneutralização em microplacas, segundo Pituco (1988). Os soros foram inativados a $560 \mathrm{C}$ por 30 minutos e a seguir $50 \mathrm{~mL}$ de uma diluição de 1:2 foi distribuída em 4 cavidades da microplaca. Desta forma, em cada placa foram testadas 22 amostras de soro. A esta diluição adicionou-se $50 \mathrm{~mL}$ da amostra de vírus padrão IBR LA contendo 200 DICT50 em $50 \mathrm{~mL}$. As microplacas foram incubadas durante 4 horas, em estufa a $37 \mathrm{oC}$ contendo $5 \%$ de $\mathrm{CO} 2$. Após este período, adicionou-se $50 \mathrm{~mL}$ de uma suspensão de células MDBK, contendo 3×105 células/ml, em cada cavidade e incubadas nas mesmas condições anteriores por 72 horas. A leitura foi realizada em microscópio invertido, para visualização do efeito citopático. Foram consideradas positivas as amostras que neutralizaram $50 \%$ das cavidades, calculadas de acordo com o método de Reed \& Müench 
(1938). Paralelamente, foram realizados controles da suspensão celular, da titulação do vírus, amostra de soro padrão positivo com títulos previamente determinados e soro padrão negativo.

Taxas de prevalência e incidência no rebanho em estudo foram calculadas segundo Côrtes (1993).

\section{RESULTADOS E DISCUSSÃO}

A prevalência e incidência da infecção pelo BHV-1 no rebanho, nos diferentes períodos em que foram realizadas coletas de soro, estão apresentadas no Quadro 1. O primeiro levantamento sorológico revelou uma prevalência de $15,6 \%$, onde 24 dos 154 animais examinados foram reagentes ao BHV-1. O reexame de todos os animais um mës após não detectou soroconversão. Com relação aos exames efetuados subsequentemente, a prevalência diminuiu devido aos descartes progressivos. Observou-se o aparecimento de 2 casos novos no $15^{\circ}$ mes após o início do experimento (incidência de 1,3\%), que foram imediatamente descartados.

A prevalência para as diferentes categorias de animais na propriedade, de acordo com os diferentes meses de coleta, está apresentada no Quadro 2.

Foram identificados bezerros soropositivos até os seis meses de idade, filhos de mães soropositivas. Nos lotes de bezerros de 6 até 12 meses de idade e no de novilhas não foram detectados animais soropositivos.

Nas vacas secas, prenhes e em lactação (animais em idade produtiva e reprodutiva), a prevalência de $12,3 \%$ foi reduzida com o descarte gradual dos animais soropositivos, até que os últimos animais infectados fossem descartados.

Nos bezerros, os anticorpos colostrais persistiram até os seis meses de idade. $\mathrm{O}$ tipo de manejo ao qual foram submetidos, permanecendo com as mães apenas nas primeiras 48 horas de vida e subsequentemente sendo isolados em gaiolas ou em baias coletivas, evitou a contaminação pelo BHV-1, fato este comprovado pela ausência de animais soropositivos após os seis meses de idade. $O$ lote de novilhas também permaneceu negativo durante todas as observações. Deve-se ressaltar que não ocorreu contato direto desta categoria com animais adultos.

A deteç̧ão de animais soropositivos nos grupos de animais adultos (vacas secas, prenhes e em lactação) revelou que a fonte de infecção encontrava-se nestes lotes e, por necessidade de práticas de manejo, as novilhas, ao iniciarem a fase de reprodução e produção, passavam a conviver com animais infectados.

Para que fosse obtido rebanho de alto valor genético livre de BHV-1 sem a utilização de vacina (Straub, 1991), utilizou-se método de erradicação do BHV-1 empregado com sucesso por outros autores para bovinos de corte (Bradley 1985, Ackermann et al. 1990).

A manutenção de propriedade livre é possível, desde que continuem sendo empregadas medidas já adotadas, como a utilização de sêmen livre de BHV-1, realização de quarentena ao ingresso de bovinos na propriedade e exames sorológicos anuais, visando impedir a reintrodução do BHV-1 no rebanho. Com o conjunto destas medidas adotadas, a fazenda encontra-se há 18 meses livre do BHV-1.

\section{REFERÊNCIAS}

Ackermann M., Peterhans E. \& Wyler R. 1982. DNA of Bovine Herpesvirus type 1 in the trigeminal ganglia of latently infected calves. Am. J. Vet. Res. 43:36-40.

Ackermann M., Weber H. \& Wyler R. 1990. Aspects of Infectious Bovine Rhinotracheitis eradication programmes in a fattening cattle farm. Prev. Vet. Med. 9:121-130.

Anunciação A.V.M., Leite R. \& Moreira E.C. 1989. Presença de anticorpos para o Herpesvírus Bovino tipo 1 (BHV-1) em bovinos nos Estados de Minas Gerais, Goiás e Rio de Janeiro, através da prova de Hemaglutinação Passiva. Arq. Bras. Med. Vet. Zootec. 41:433-441.

Quadro 1. Prevalência e incidência do BHV-1 em rebanho bovino leiteiro submetido à manejo semi-intensivo (Período de 33 meses)

\begin{tabular}{lcccccccccc}
\hline \multicolumn{1}{c}{ Resultado } & \multicolumn{1}{c}{ Meses } \\
\cline { 2 - 10 } & 1 & 2 & 5 & 8 & 11 & 15 & 18 & 21 & 27 & 33 \\
\hline & & & & & & & & & \\
Número total de animais positivos & 24 & 24 & 19 & 15 & 04 & 02 & 0 & 0 & 0 & 0 \\
Número total de animais examinados & 154 & 154 & 166 & 137 & 160 & 151 & 133 & 134 & 126 & 116 \\
Prevalência & $15,6 \%$ & $15,6 \%$ & $11,5 \%$ & $10,9 \%$ & $2,5 \%$ & $1,3 \%$ & $0,0 \%$ & $0,0 \%$ & $0,0 \%$ & $0,0 \%$ \\
Número de casos novos & 0 & 0 & 0 & 0 & 0 & 02 & 0 & 0 & 0 & 0 \\
Incidência & $0,0 \%$ & $0,0 \%$ & $0,0 \%$ & $0,0 \%$ & $0,0 \%$ & $1,3 \%$ & $0,0 \%$ & $0,0 \%$ & 0,05 & $0,0 \%$
\end{tabular}

Quadro 2. Prevalência de anticorpos anti - BHV-1 em rebanho leiteiro submetido a manejo semi-intensivo, segundo diferentes grupos de animais (Período de 33 meses)

\begin{tabular}{|c|c|c|c|c|c|c|c|c|c|c|}
\hline \multirow[t]{2}{*}{ Grupos de Animais } & \multicolumn{10}{|c|}{ Meses } \\
\hline & 1 & 2 & 5 & 8 & 11 & 15 & 18 & 21 & 27 & 33 \\
\hline Bezerros $<6$ meses de idade & $\begin{array}{c}05 \\
(3,3 \%)\end{array}$ & $\begin{array}{c}05 \\
(3,3 \%)\end{array}$ & $\begin{array}{c}02 \\
(1,2 \%)\end{array}$ & $\begin{array}{c}02 \\
(1,5 \%)\end{array}$ & $\begin{array}{c}0 \\
(0,0 \%)\end{array}$ & $\begin{array}{c}0 \\
(0,0 \%)\end{array}$ & $\begin{array}{c}0 \\
(0,0 \%)\end{array}$ & $\begin{array}{c}0 \\
(0,0 \%)\end{array}$ & $\begin{array}{c}0 \\
(0,0 \%)\end{array}$ & $\begin{array}{c}0 \\
(0,0 \%)\end{array}$ \\
\hline $\begin{array}{l}\text { Bezerros de } 6 \text { a } 12 \text { meses de idade } \\
\text { e novilhas }\end{array}$ & $\begin{array}{c}0 \\
(0,0 \%)\end{array}$ & $\begin{array}{c}0 \\
(0,0 \%)\end{array}$ & $\begin{array}{c}0 \\
(0,0 \%)\end{array}$ & $\begin{array}{c}0 \\
(0,0 \%)\end{array}$ & $\begin{array}{c}0 \\
(0,0 \%)\end{array}$ & $\begin{array}{c}0 \\
(0,0 \%)\end{array}$ & $\begin{array}{c}0 \\
(0,0 \%)\end{array}$ & $\begin{array}{c}0 \\
(0,0 \%)\end{array}$ & $\begin{array}{c}0 \\
(0,0 \%)\end{array}$ & $\begin{array}{c}0 \\
(0,0 \%)\end{array}$ \\
\hline Vacas secas, prenhes e em lactação & $\begin{array}{c}19 \\
(12,3 \%)\end{array}$ & $\begin{array}{c}19 \\
(12,3 \%)\end{array}$ & $\begin{array}{c}17 \\
(10,2 \%)\end{array}$ & $\begin{array}{c}13 \\
(9,5 \%)\end{array}$ & $\begin{array}{c}04 \\
(2,5 \%)\end{array}$ & $\begin{array}{c}02 \\
(1,3 \%)\end{array}$ & $\begin{array}{c}0 \\
(0,0 \%)\end{array}$ & $\begin{array}{c}0 \\
(0,0 \%)\end{array}$ & $\begin{array}{c}0 \\
(0,0 \%)\end{array}$ & $\begin{array}{c}0 \\
(0,0 \%)\end{array}$ \\
\hline Número total de animais examinados & 154 & 154 & 166 & 137 & 160 & 151 & 133 & 134 & 126 & 116 \\
\hline
\end{tabular}


Bradley J.A. 1985. Eradication of Infectious Bovine Rhinotracheitis Vírus (Bovine Herpesvirus 1) from a herd of beef cattle. Can. Vet. J. 26:195-198.

Côrtes J.A. 1993. Epidemiologia, conceitos e princípios fundamentais. Livraria Varela, São Paulo, p. 151-155.

Embrapa 1978. Diretório da Embrapa 1978. $3^{a}$ edição. Depto Informação e Documentação, Brasília, p. 300-301.

Lemaire M., Pastoret P.P. \& Thiry E. 1994. Le contrôle de l'infection pas le virus de la rhinotrachéite infectieuse bovine. Ann. Méd. Vét. 138:167-180.

Lovato L.T., Weiblein R., Tobias F.L. \& Moraes M.P. 1995. Herpesvírus Bovino tipo 1 (BHV-1): inquérito soro-epidemiológico no rebanho leiteiro do Estado do Rio Grande do Sul, Brasil. Ciência Rural, Santa Maria, 25:425-430.

Office International des Epizooties 1995. International Animal Health Code. 5th ed. OIE, Paris.
Pituco E.M. 1988 Ocorrência da Rinotraqueíte Infecciosa dos Bovinos/ Vulvovaginite Pustular Infecciosa (IBR/IPV) em rebanhos criados nos Estados de São Paulo, Rio Grande do Sul, Paraná e Minas Gerais. Tese de Mestrado, FMVZ-USP, São Paulo. 74p.

Reed L.J. \& Muench, H. 1938. A simple method of estimating 50 per cent end point. Am. J. Hyg. 27:493-497.

Roizman B., Desrosiers R.C., Fleckenstein B., Lopez C., Minson A.C. \& Studdert M.J. 1995. Family Herpesviridae. Arch. Virol. supl. 10:114127.

Straub O.C. 1991. BHV 1 Infection: relevance and spread in Europe. Comp. Immun. Microbiol. Infect. Dis. 14:175-186.

Vidor T., Halfen D.C., Leite T.E. \& Coswig L.T. 1995. Herpes Bovino tipo 1 (BHV-1) I. Sorologia de rebanhos com problemas reprodutivos. Ciência Rural, Santa Maria, 25:421-424. 